\section{POS1064 SERUM BIOMARKERS BEFORE AND AFTER A SIX MONTHS STRUCTURED WEIGHT LOSS INTERVENTION IN PATIENTS WITH PSORIATIC ARTHRITIS AND OBESITY COMPARED WITH CONTROLS}

L. Torres ${ }^{1}$, C. Jonsson ${ }^{1}$, B. Eliasson ${ }^{2}$, H. Forsblad-D'elia ${ }^{1}$, A. Bilberg ${ }^{3}$, I. Gjertsson ${ }^{1}$, I. Larsson ${ }^{4}$, E. Klingberg ${ }^{1}{ }^{1}$ University of Gothenburg, Department of Rheumatology and Inflammation Research, Gothenburg, Sweden; ${ }^{2}$ Institute of Medicine, Sahlgrenska University Hospital, University of Gothenburg, Sweden, Department of Medicine, Gothenburg, Sweden; ${ }^{3}$ Institute of Neuroscience and Physiology, Sahlgrenska Academy at the University of Gothenburg, Sweden, Section of Health and Rehabilitation, Physiotherapy, Gothenburg, Sweden; ${ }^{4}$ Institute of Medicine, Sahlgrenska Academy at University of Gothenburg, Sweden, Department of Gastroenterology and Hepatology, Gothenburg, Sweden

Background: Obesity is highly overrepresented in psoriatic arthritis (PsA) and associated with increased disease activity. We have previously shown in 41 patients with PsA (Caspar criteria) and obesity (here body mass index BMI $\geq 33 \mathrm{~kg} / \mathrm{m}^{2}$ ) that weight loss treatment including Very Low Energy Liquid Diet (VLED) resulted in a median weight loss of $18.6 \%$ and concomitantly a significant improvement in CRP and disease activity in joints, entheses and skin at six months (M6) follow up.

Objectives: To analyze serum biomarkers associated with inflammation, cartilage and bone metabolism before and after weight loss treatment in PsA patients compared with controls, without PsA or psoriasis, matched for age, sex and weight.

Methods: The weight loss treatment included VLED (640 kcal/day) during 12 or 16 weeks (depending on baseline (BL) BMI $<40$ or $\geq 40 \mathrm{~kg} / \mathrm{m}^{2}$ ), followed by a structured reintroduction of an energy restricted diet. cs/bDMARDs were held unchanged from 3 months before BL until M6. The patients were assessed with $66 / 68$ joints counts.

Serum levels of vascular endothelial growth factor (VEGF), S100A8, S100A9, matrix metalloproteinases (MMP-3, 8 and 13), hepatocyte growth factor (HGF), B-cell activating factor (BAFF), Dickkopf (DKK)-1, sclerostin (SOST), soluble receptor activator of nuclear factor-kB ligand (RANKL), osteprotegerin (OPG) and aggrecan were measured at BL and M6 in PsA patients and controls with Magnetic Luminex Assays (R\&D-systems) following the manufacturer's instructions using a Bio-Plex 200 system (BioRad). Serum cartilage oligomeric matrix protein (COMP) (R\&D-systems), carboxyterminal telopeptide of type- 1 collagen (CTX-1) (Immunodiagnostics systems: IDS) and osteocalcin (IDS) were measured with enzyme-linked immunosorbent assay (ELISA).

Results: Totally 41 PsA patients [age median 54 (IQR 48-62) yrs; $63 \%$ women] and 39 controls [age 55 (46-60) yrs, $72 \%$ women] were included. At M6 the weight-loss since BL was 18.7 (14.6-26.5) $\mathrm{kg}$ in the PsA patients and 22.6 (14.7$28.4) \mathrm{kg}$ in the controls $(\mathrm{p}=0.546)$. Significant reductions in DAS28CRP [2.9 (2.1$3.7)$ vs. $2.4(1.7-3.0)]$ and DAPSA [15.3(6.6-29.1) vs. $11.0(2.8-17.6)](p<0.001)$ were seen in the PsA patients.

At $B L$ serum levels of the biomarkers were not significantly different in patients vs. controls.

After weight-loss significant reductions were seen in serum VEGF, S100A8, MMP-8, HGF, BAFF, COMP and DKK-1, whereas serum SOST and CTX-1 were significantly increased in both patients and controls (Table 1). The other biomarkers were not significantly changed.

Conclusion: Weight loss in patients with PsA and controls was associated with lowered serum levels of several biomarkers related to inflammation and cartilage degradation, along with increased levels of biomarkers for bone turnover.

Disclosure of Interests: None declared.

DOI: 10.1136/annrheumdis-2021-eular.999

Table 1.

\begin{tabular}{|c|c|c|c|c|c|c|}
\hline & $\operatorname{PsA}(\mathrm{N}=41)$ & PsA $(N=41)$ & PsA & $\mathrm{Ctrl}(\mathrm{N}=39)$ & $\operatorname{Ctrl}(\mathrm{N}=39)$ & Ctrl \\
\hline BMI $\left(\mathrm{kg} / \mathrm{m}^{2}\right)$ & $35.2(34.1-38.1)$ & $29.8(26.6-31.5)$ & $<0.001$ & 37.7 (36.7-41.5) & $30.4(27.9-33.2)$ & $<0.001$ \\
\hline $\operatorname{VEGF}(\mathrm{pg} / \mathrm{mL})$ & $79.6(55.9-113.5)$ & $69.6(53.1-105.3)$ & 0.010 & $82.3(48.0-125.9)$ & $65.0(42.2-85.5)$ & $<0.001$ \\
\hline S100A8 (pg/mL) & 75.5 (48.0-99.5) & $63.3(42.8-93.6)$ & 0.021 & $71.8(40.5-101.0)$ & $63.3(40.3-85.7)$ & 0.006 \\
\hline MMP-8 (pg/mL) & 9975.4 & 9202.6 & 0.017 & 7494.7 & 7218.3 & 0.112 \\
\hline & $(6811.8-14154.8)$ & (5767.1-12049.6) & & $(4805.2-12616.9)$ & $(3466.0-9785.3)$ & \\
\hline HGF (pg/mL) & $327.9(250.3-413.6)$ & $271.3(206.9-331.0)$ & $<0.001$ & 307.9 (239.1-348.3) & $239.8(200.3-276.0)$ & $<0.001$ \\
\hline Dkk-1 (pg/mL) & 3608.4 & 3382.6 & 0.002 & 3635.8 & 3480.4 & 0.007 \\
\hline & $(3055.0-4401.3)$ & (2802.5-4218.2) & & $(3212.8-4380.6)$ & (2948.9-4087.3) & \\
\hline SOST (pg/mL) & $52.9(32.5-65.4)$ & $60.3(37.2-85.6)$ & 0.014 & $50.0(30.8-79.3)$ & $61.3(35.7-81.4)$ & 0.019 \\
\hline CTX-1 $(\mathrm{ng} / \mathrm{mL})$ & $0.27(0.20-0.39)$ & $0.51(0.35-0.64)$ & $<0.001$ & $0.23(0.16-0.34)$ & $0.50(0.30-0.61)$ & $<0.001$ \\
\hline
\end{tabular}

\section{POS1065 CIRCULATING ENDOTHELIAL CELLS AS A MARKER OF CARDIOVASCULAR DISEASES IN PATIENTS WITH PSORIATIC ARTHRITIS}

S. Smiyan ${ }^{1}$, A. Bilukha ${ }^{1}$, B. Koshak ${ }^{1} .^{1}$ Ternopil State Medical University, Internal Medicine №2, Ternopil, Ukraine

Background: Psoriatic arthritis (PsA) is a chronic inflammatory joint disease which develops in patients with psoriasis. Mortality among patients with PsA is 1.28 times higher than population levels and in most cases it is caused by cardio-vascular diseases (CVD). Those patients have increased risk of clinical and subclinical CVD, mostly due to endothelial dysfunction (ED) and accelerated atherosclerosis. Elevated levels of circulating endothelial cells (CEC) have been described in different cardiovascular pathologies, suggesting their potential use as diagnostic biomarkers for dysfunction of endothelium.

Objectives: To identify the potential role of circulating endothelial cells as a marker of cardiovascular diseases in patients with psoriatic arthritis.

Methods: In total, ninety-four patients with PsA, who fulfilled the disease criteria (CASPAR) were examined using standard diagnostic methods (including C-reactive protein (CRP), lipid profile) and evaluation endothelium-dependent vasodilation in response to reactive hyperemia (EDVD). Circulating endothelial cells were determined in the peripheral venous blood samples by flow cytometry and counted according to a standardized protocol using a fluorescence microscope after acridine orange labeling. The control group, which were consisted from thirty healthy adults were also examined.

Results: CEC were quantified in patients with PsA $\left(7,15 \pm 0,19\right.$ cells $\left.\mathrm{mL}^{-1}\right)$ and in the control group $\left(4,05 \pm 0,11\right.$ cells $\left.\mathrm{mL}^{-1}\right)$. Comparing two groups of patients, endothelial circulating cell level was significantly different $(p=0.0001)$. Finally, we analyzed the relationship between CEC count, comorbidities, cardiovascular risk factors and EDVD in patients with PsA. Increased CEC levels were associated with obesity $(r=0,62)$, duration of disease $(r=0,65)$, age $(r=0,67)$, increased CRP $(r=0,76)$, high blood pressure $(r=0,87)$ and decreased EDVD $(r=-0,91)$.

Conclusion: CEC counts were significantly higher in patients with PsA, positively correlated with the main factors of CVD, and another specific marker of ED - EDVD. Elevated CEC levels were also associated with high concentrations of CRP, which plays a direct role in promoting vascular inflammation, vessel damage and clinical CVD events. In conclusion, increased CEC counts provide a direct proof of endothelial damage in patient with PsA and a clinically informative diagnostic tool for endothelial damage in pre-symptomatic CVD. As CEC are one of the most sensitive biomarker for ED, further efforts should concentrate on improving the sensitivity of its detection in order to increase diagnostic sensitivity. REFERENCES:

[1] Maura Farinacci, Thomas Krahn, Wilfried Dinh, et al. Circulating endothelial cells as biomarker for cardiovascular diseases. Res Pract Thromb Haemost, Vol. 3, Issue, 2019, P.49-58;

[2] C. Horreau, C. Pouplard, E. Brenautet, et al. Cardiovascular morbidity and mortality in psoriasis and psoriatic arthritis: a systematic literature review. J Eur Acad Dermatol Venereol, Vol. 27, Issue 3, 2013, P.12-19;

[3] Frank Verhoeven, Clément Prati, Céline Demougeot, Daniel Wendling. Cardiovascular risk in psoriatic arthritis, a narrative review. Joint Bone Spine, Vol. 87, Issue 5, 2020, P.413-418;

Disclosure of Interests: None declared.

DOI: 10.1136/annrheumdis-2021-eular.1000

\begin{tabular}{|l|l}
\hline POS1066 & IS ENTHESITIS A SONOGRAPHIC BIOMARKER OF \\
DISEASE SEVERITY IN PSORIATIC ARTHRITIS? THE LINK \\
BETWEEN ULTRASOUND ENTHESEAL ABNORMALITIES \\
AND PERIPHERAL JOINT EROSIVE DAMAGE
\end{tabular}

G. Smerilli' ${ }^{1}$, E. Cipolletta ${ }^{1}$, G. M. Destro Castaniti ${ }^{2}$, A. DI Matteo ${ }^{1}$, M. DI Carlo ${ }^{1}$, E. Moscioni ${ }^{1}$, F. Francioso ${ }^{1}$, W. Grassi ${ }^{1}$, E. Filippucci ${ }^{1}{ }^{1}{ }^{1}$ Marche Polytechnic 
University, Rheumatology Unit, Department of Clinical and Molecular Sciences, "Carlo Urbani" Hospital, Jesi, Italy; ${ }^{2}$ University of Palermo, Department of Health Promotion, Mother and Child Care, Internal Medicine and Medical Specialties, Rheumatology section, "P. Giaccone" Hospital, Palermo, Italy

Background: Enthesitis is one of the hallmark of psoriatic arthritis (PsA). Ultrasound (US) accurately detects morphostructural abnormalities indicative of entheseal inflammation and structural damage. Interestingly, in a recent study, US-detected entheseal pathology appeared to be a potential marker of disease severity, being associated with higher radiographic score of structural damage at peripheral joint level. (1) However, a sub-analysis of the impact of each elementary finding of US enthesitis was not performed. Moreover, some US entheseal abnormalities (hypoechogenicity, thickening and calcification/enthesophyte) have been described as frequent findings in healthy subjects and patients with dysmetabolic conditions, undermining their specificity. (2) Thus, we hypothesized that their role as a sonographic biomarker of joint disease severity could be questioned.

Objectives: The main aim of the present study was to explore the association between the US elementary findings of enthesitis defined by OMERACT [i.e. hypoechogenicity, thickening, Doppler signal, calcification/enthesophyte and bone erosion at enthesis] (3) and the presence of US-detected joint bone erosions in patients with PsA.

Methods: Consecutive patients with PSA (CASPAR criteria) were included in this cross-sectional single-centre study. The scanning protocol included bilateral assessment of the main entheses of the lower limbs [plantar fascia, quadriceps, patellar (proximal and distal) and Achilles tendons]. The presence of US joint bone erosions was investigated in the following areas: 2nd and 5th metacarpophalangeal (MCP) joints, ulnar head and 5th metatarsophalangeal (MTP) joint, bilaterally, as well as the most inflamed joint at the physical examination. The US examination was carried out with a 6-18 $\mathrm{MHz}$ probe. Univariate and multivariate logistic analysis were performed to identify predictors of US joint bone erosions.

Results: A total of 74 PsA patients were enrolled. The mean disease duration was $7.9 \pm 8.0$ years. Joint bone erosions were found in $36 / 75$ patients $(48.0 \%)$, and in $71 / 600$ joints (11.8\%), most frequently in the 5 th MTP joint (in $26 / 75$ patients, $34.7 \%$ ). The univariate analysis showed that entheseal bone erosions [odds ratio (OR) 27.1, 95\% confidence interval $(\mathrm{Cl}) 3.3-220.2$, p value $<0.01$ ] and Doppler signa (OR 3.5, 95\% Cl 1.3 - 9.4, p value 0.01 ) were associated with joint bone erosions Only entheseal bone erosions remained significantly associated with joint bone erosions in the multivariate analysis (Table 1).

Table 1. Multivariate regression analysis: predictive value of the entheseal US findings for the presence of joint bone erosions.

\begin{tabular}{lll}
\hline & OR $\mathbf{( 9 5 \% ~ C l )}$ & P value \\
\hline Hypoechogenicity & $0.5(0.1-3.4)$ & 0.45 \\
Thickening & $2.2(0.6-8.3)$ & 0.27 \\
Doppler signal & $3.2(0.9-10.8)$ & 0.06 \\
Calcification/enthesophyte & $1.1(0.1-11.2)$ & 0.99 \\
Entheseal bone erosion & $24.2(2.7-216.2)$ & $<0.01$ \\
\hline
\end{tabular}

Conclusion: Entheseal bone erosion and, to a lesser extent, Doppler signal, were the only entheseal abnormalities correlated with the presence of US-detected joint bone erosions, representing potential sonographic biomarkers of disease severity in PsA.

\section{REFERENCES:}

[1] Polachek A, Cook R, Chandran V, Gladman DD, Eder L. The association between sonographic enthesitis and radiographic damage in psoriatic arthritis. Arthritis Res Ther 2017; 15;19:189.

[2] Balint PV, Terslev L, Aegerter P, Bruyn GAW, Chary-Valckenaere I, Gandjbakhch $F$, et al. Reliability of a consensus-based ultrasound definition and scoring for enthesitis in spondyloarthritis and psoriatic arthritis: An OMERACT US initiative. Ann Rheum Dis 2018; 77(12):1730-5

[3] Di Matteo A, Filippucci E, Cipolletta E, Martire V, Jesus D, Musca A, et al. How normal is the enthesis by ultrasound in healthy subjects? Clin Exp Rheumatol 2020;38:472-8.

Disclosure of Interests: Gianluca Smerilli: None declared, Edoardo Cipolletta: None declared, Giulia Maria Destro Castaniti: None declared, Andrea Di Matteo: None declared, Marco Di Carlo: None declared, Erica Moscioni: None declared, Francesca Francioso: None declared, Walter Grassi Speakers bureau: W.G. has received speaking fees from AbbVie, Celgene, Grünenthal, Pfizer and UCB Pharma., Emilio Filippucci Speakers bureau: E.F. has received speaking fees from Abbvie, BMS, Janssen, Lilly, MSD, Novartis, Roche, Pfizer, UCB Pharma. DOI: 10.1136/annrheumdis-2021-eular.1159

\begin{tabular}{|l|l}
\hline POS1067 & BASELINE VITAMIN D LEVELS AND DISEASE \\
& ACTIVITY AND RESPONSE IN PORTUGUESE \\
& PATIENTS WITH PSORIATIC ARTHRITIS UNDER \\
& BMDARD: DOES IT MAKE A DIFFERENCE?
\end{tabular}

F. Oliveira Pinheiro ${ }^{1}$, B. M. Fernandes ${ }^{1}$, S. Garcia ${ }^{1}$, M. Rato ${ }^{1}$, D. Fonseca ${ }^{2}$, D. Santos Oliveira ${ }^{1,3}$, A. Martins ${ }^{1}$, F. R. Martins ${ }^{4}$, P. Madureira ${ }^{1}$, M. Bernardes ${ }^{1,5}$,
L. Costa ${ }^{1}{ }^{1}$ Centro Hospitalar Universitário de São João, Rheumatology Department, Porto, Portugal; ${ }^{2}$ Centro Hospitalar Vila Nova de Gaia/Espinho, Rheumatology Department, Vila Nova de Gaia, Portugal; ${ }^{3}$ Faculty of Medicine, University of Porto, Center for Health Technology and Services Research (CINTESIS), Porto, Portugal; ${ }^{4}$ Centro Hospitalar Universitário do Algarve, Rheumatology Department, Faro, Portugal; ${ }^{5}$ Faculty of Medicine, University of Porto, Medicine Department, Porto, Portugal

Background: There is growing evidence that vitamin D [25(OH)D]) plays an important role in maintaining skeletal health and modulating the immune system. Epidemiological data indicate that vitamin D deficiency is common in immune-mediated rheumatic diseases, especially in rheumatoid arthritis, but there is little data regarding its association with disease activity and response to therapy in patients with psoriatic arthritis (PsA) under bDMARD therapy.

Objectives: We aimed to assess whether 25(OH)D basal levels correlate with disease activity and clinical response to the first bDMARD, at 6 and 12 months of therapy, in a monocentric cohort of patients with PsA.

Methods: This retrospective study was carried out on PSA patients from a Rheumatology department of a tertiary hospital, fulfilling CASPAR criteria and registered in our national database (Reuma.pt), who started the first bDMARD since 2008 Demographic, clinical and laboratory criteria were evaluated at 0, 6 and 12 months of biologic therapy. Disease activity was assessed using CDAI, SDAI, DAS28(4V), BAS DAI, ASDAS, DAPSA and the response was measured using the EULAR, BASDAI50, ASDAS, ASAS, ACR and PSARC responses. Correlations were made between absolute serum levels of $25(\mathrm{OH}) \mathrm{D}$ and continuous variables, as well as associations between different vitamin $\mathrm{D}$ cutoffs and disease activity measures and response criteria. Multiple linear and logistic regression analyses were performed to determine whether vitamin $\mathrm{D}$ is a predictor of disease activity and therapeutic response.

Results: We included 81 patients, $41(50.6 \%)$ females; with a mean age of $48.0 \pm 11.7$ years, a mean disease duration of $9.5 \pm 7.4$ years and a mean body mass index of $28.4 \pm 5.2 \mathrm{~kg} / \mathrm{m} 2$. Thirteen $(16.0 \%)$ were smokers. The mean $25(\mathrm{OH}) \mathrm{D}$ basal level was $25.5 \pm 13.2 \mathrm{ng} / \mathrm{ml}, 21(25.9 \%)$ had $25(\mathrm{OH}) \mathrm{D}$ basal levels $\geq 30 \mathrm{ng} / \mathrm{mL}$ and $31(38.3 \%)$ $\leq 20 \mathrm{ng} / \mathrm{mL}$. Sixty-two patients $(76.5 \%)$ were under csDMARD therapy. Golimumab (29 $35,8 \%)$, etanercept $(28,34.6 \%)$ and adalimumab $(10,12.3 \%)$ were the most frequently prescribed bDMARDs. There were only very weak, albeit positive, correlations between $25(\mathrm{OH}) \mathrm{D}$ levels and measures of disease activity. The BASDAI50 response at 6 months was associated with higher basal $25(\mathrm{OH}) \mathrm{D}$ levels $(29.5 \pm 14.5$ vs $21.5 \pm 10.2 \mathrm{ng} / \mathrm{mL}, \mathrm{p}=$ $0.013)$; the ASAS20 ( $33.9 \pm 15.9$ vs $24.2 \pm 12.8 \mathrm{ng} / \mathrm{mL} ; \mathrm{p}=0.023)$, ASAS40 $(31.9 \pm 14.6$ vs $25.0 \pm 13.8 \mathrm{ng} / \mathrm{mL} ; p=0.023)$ and ASAS70 (47.0 \pm 4.2 vs $26.6 \pm 14.2 ; p=0.027)$ responses at 12 months were associated with higher basal levels of $25(\mathrm{OH}) \mathrm{D}$; basal $25(\mathrm{OH}) \mathrm{D}$ levels were $\geq 30 \mathrm{ng} / \mathrm{mL}$ in a significantly higher proportion of patients who achieved CDAI (38.9\% vs $10.5 \% ; p=0.027)$ and SDAI (38.9\% vs $7.7 \% ; p=0.008)$ remission and ASDAS disease inactive $(29.4 \%$ vs $7.3 \% ; p=0.040)$ at 1 year. In the regression models, basal levels of $25(\mathrm{OH}) \mathrm{D}$ were found to be predictors of good EULAR responders (OR $1.315,1.017-1.21395 \% \mathrm{Cl} ; \mathrm{p}=0.037)$ at 6 months. Basal levels of $25(\mathrm{OH}) \mathrm{D}$ were not significantly different in patients who discontinued bDMARD and no significant correlations or associations were identified regarding more specific PsA activity measures, such as DAPSA and PSARC, nor were they predictive of these responses.

Conclusion: We can conclude that there is a global trend for an association between higher levels of vitamin $\mathrm{D}$ and lower measures of disease activity and better therapeutic responses to the first biologic. It was possible to find statistically significant associations with some disease activity measures and response criteria that although primarily designed for other rheumatic diseases, are often used in PsA.

Disclosure of Interests: None declared.

DOI: 10.1136/annrheumdis-2021-eular.1255

\section{POS1068 \\ CARDIAC BIOMARKERS ARE ASSOCIATED WITH THE DEVELOPMENT OF CARDIOVASCULAR EVENTS IN} PATIENTS WITH PSORIATIC ARTHRITIS AND PSORIASIS

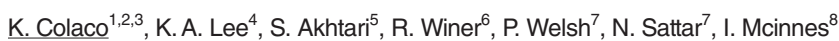
V. Chandran ${ }^{9,10}$, P. Harvey ${ }^{5,9}$, R. Cook $^{4}$, D. D. Gladman ${ }^{9,10}$, V. Piguet ${ }^{1,9}$, L. Eder $^{1,9}$. ${ }^{1}$ Women's College Hospital, Women's College Research Institute, Toronto, Canada; ${ }^{2}$ University Health Network, Krembil Research Institute, Toronto, Canada; ${ }^{3}$ University of Toronto, Institute of Medical Science, Toronto, Canada; ${ }^{4}$ University of Waterloo, Statistics and Actuarial Science, Waterloo, Canada; ${ }^{5}$ Women's College Hospital, Cardiology, Toronto, Canada; ${ }^{6}$ Rambam Health Care Campus, Neurology, Haifa, Israel; ${ }^{7}$ University of Glasgow, Institute of Cardiovascular \& Medical Sciences, Glasgow, United Kingdom; ${ }^{8}$ University of Glasgow, Institute of Infection, Immunity and Inflammation, Glasgow, United Kingdom; ${ }^{9}$ University of Toronto, Medicine, Toronto, Canada; ${ }^{10}$ University Health Network, Centre for Prognosis Studies in the Rheumatic Diseases, Toronto, Canada

Background: N-terminal pro-brain-type natriuretic peptide (NT-proBNP) and troponin I (Tnl) are established cardiac biomarkers that predict cardiovascular events (CVEs) in the general population. While patients with psoriatic arthritis and psoriasis, collectively termed psoriatic disease (PsD), have an increased risk of developing CVEs, the use of these cardiac biomarkers to predict CV risk has not been investigated in this population. 